http://journal.nafo.int

J. Northw. Atl. Fish. Sci., Vol. 3: 41-45

\title{
Embryonic Development of the Squid, Illex illecebrosus, and Effect of Temperature on Development Rates
}

\author{
R. K. O'Dor, N. Balch, E. A. Foy, R. W. M. Hirtle, D. A. Johnston \\ Dalhousie University \\ Halifax, Nova Scotia, Canada B3H 4J1 \\ and \\ T. Amaratunga \\ Department of Fisheries and Oceans, Invertebrates and Marine Plants Division \\ P. O. Box 550, Halifax, Nova Scotia, Canada B3J 257
}

\begin{abstract}
Development stages for artifically fertilized and naturally spawned eggs of Illex illecebrosus were observed and a staging scheme proposed which relates to earlier studies on naturally spawned eggs of Illex coindetii and artifically fertilized eggs of Todarodes pacificus. Photographs and descriptions of stages provide a reference for embryonic development of small ommastrephid eggs and an aid to the identification of egg masses of the species in nature, an essential step in understanding its life cycle. Embryonic development in I. illecebrosus fails at temperatures below $12.5^{\circ} \mathrm{C}$, and the development rate at $21^{\circ} \mathrm{C}$ is nearly twice that at $12.5^{\circ} \mathrm{C}$. This temperature requirement restricts the spatial and temporal distribution of spawning in this squid, and temperature-related development rates allow prediction of the age of egg masses found in nature in water masses of a particular temperature.
\end{abstract}

\section{Introduction}

The short-finned squid, I. illecebrosus, is the subject of an increasingly important fishery in the Northwest Atlantic, and information on its reproductive biology is a key to understanding the life cycle and managing the fishery (NAFO, 1980). The only previously published record of the embryonic development of squid of the genus IIlex is that of Naef (1923) for an unknown cephalopod subsequently identified as IIlex coindetii (Boletzky et al., 1973). Naef's description is incomplete in that he figured only the evennumbered stages from VIII to XX. Hayashi (1960) and Hamabe (1962) have published comprehensive illustrations of the development of another ommastrephid, Todarodes pacificus, but have not proposed or adopted a scheme of egg development stages. Such a scheme is necessary to evaluate the effects of environmental variables such as temperature on development rates.

The embryonic development of large-egged cephalopods have been found to be generally highly temperature dependent (Boletzky, 1974). This paper presents some experimental results of the effects of changes in temperature on the smaller eggs of $/$. illecebrosus and provides a photographic record of embryonic development stages which may aid in the identification of egg masses of this squid in the field and allow the age of such masses to be estimated.

\section{Materials and Methods}

Both normally spawned and artifically fertilized eggs of $I$. illecebrosus have been studied. Early maturation, mating and spawning were induced in squid held in a 15-m diameter pool at the Aquatron Laboratory of Dalhousie University, Halifax, Nova Scotia, under conditions previously described by O'Dor et al., (1977). Such animals produced large spherical gelatinous egg masses up to $1 \mathrm{~m}$ in diameter containing up to 100,000 eggs (Durward et al., 1980). Although the females usually died a few days after spawning, they still contained eggs within their oviducts and spermatophores attached inside their mantles; these were used for in vitro fertilization experiments.

Between 1978 and 1981, over 30 normal egg masses were observed at temperatures between $7^{\circ}$ and $22^{\circ} \mathrm{C}$. In situ photographic surveys were made of large egg masses by lowering a glass-bottom caisson ( $4 \mathrm{~m}$ deep and $30 \mathrm{~cm}$ diameter) over them. Some large masses were trapped in plankton nets and brought to the surface or to the side window of the pool for microscopic observations. Surveys to determine fertilization rates and developmental stages were made with a dissecting microscope, counting eggs while focusing through the mass. Microphotographic and videotape records of egg development in small intact masses, trapped and held in small temperaturecontrolled aquaria, were also made. Before 1981, all 
observations in the pool were made at ambient seawater temperatures which occasionally reached $17^{\circ} \mathrm{C}$ in September but were typically between $7^{\circ}$ and $10^{\circ} \mathrm{C}$ during October-November when most of the spawning occurred. In 1981, provision for heating and cooling allowed the maintenance of temperature between $13^{\circ}$ and $16^{\circ} \mathrm{C}$ throughout the period.

The three principal in vitro experiments are outlined in Table 1. Several hundred spermatophores were cut into $1-\mathrm{mm}$ segments in $10 \mathrm{ml}$ of seawater and the container shaken gently for an hour at room temperature to produce a milky suspension containing approximately $10^{7} \mathrm{sperm} / \mathrm{ml}$. Aliquots were fixed in $10 \%$ formalin and sperm counts determined with a hemocytometer. Aliquots producing titers of about $4 \mathrm{x}$ $10^{4} \mathrm{sperm} / \mathrm{ml}$ were then added to the flasks containing several thousand eggs in $200 \mathrm{ml}$ of seawater for fertilization, as indicated in Table 1. After the fertilization period, the eggs were rinsed three times in sterile seawater containing 500 units/ml of penicillinstreptomycin-fungizone and transferred to sterile petridishes containing 10 or $50 \mathrm{ml}$ of the same medium. Dishes containing about 1,000 eggs were incubated as indicated in Table 1. In some experiments, individual eggs in multi-welled tissue culture plates were observed daily.

Initial surveys to determine fertilization rates were made by counting several hundred eggs in random squares of dishes placed over a grid under a dissecting microscope. Detailed surveys to determine development stages were made by counting random fields using a Zeiss inverted microscope; photographs were taken with this system. Time-lapse video recordings made with this microscope were used to study early cell cleavage. To minimize heating during prolonged observation under the microscope, the dishes were placed in a small glass aquarium at the appropriate water temperature and the aquarium placed on the microscope stage.

\section{Results}

\section{Development pattern}

An essentially complete record of the embryonic development of I. illecebrosus, based on observations of early stages from artifically fertilized eggs and later stages from normal egg masses, is shown in Fig. 1. After fertilization, an intrachorionic space appears near the micropyle (Fig. 1A) and two polar bodies are ejected. The meroblastic cleavages (Fig. 1B) at the animal pole resemble those seen in other cephalopods (Naef, 1923; Arnold, 1965), and the entire development pattern is similar to that of T. pacificus (Hayashi, 1960; Hamabe, 1962). After about the tenth cleavage, the blastoderm delaminates to form a trilaminar blastodisc at the animal pole (Fig. 1C) and then continues to grow downward (Fig. 1D) until the entire surface is celluated. Thickened placodes overlying the central yolk mass form the primordia of the various organs. The pigmentation of the eye placodes near the vegetal pole makes them prominent (Fig. 1E, F). In normally spawned eggs within the mass of nidamental gel, the chorion begins to expand (stage IX) and may increase to 3-4 times its original diameter before hatching occurs. However, no chorion expansion occurred in the in vitro experiments, and development beyond this stage was abnormal. Major indicators for the various stages are noted in the legend of Fig. 1. The larvae

TABLE 1. Development of $I$. illecebrosus eggs in vitro under various conditions (Sperm titers used contained approximately $40,000 \mathrm{sperm} / \mathrm{ml}$.)

\begin{tabular}{|c|c|c|c|c|c|c|}
\hline \multirow[b]{2}{*}{ Expt. } & \multicolumn{2}{|c|}{ Fertilization } & \multicolumn{2}{|c|}{ Incubation } & \multirow{2}{*}{$\begin{array}{c}\text { Development } \\
\text { stage } \\
\text { reached }\end{array}$} & \multirow{2}{*}{$\begin{array}{c}\text { Fertil- } \\
\text { ization } \\
\text { rate } \\
(\%)\end{array}$} \\
\hline & $\begin{array}{c}\text { Temperature } \\
\left({ }^{\circ} \mathrm{C}\right)\end{array}$ & $\begin{array}{l}\text { Duration } \\
(\mathrm{hr})\end{array}$ & $\begin{array}{c}\text { Temperature } \\
\left({ }^{\circ} \mathrm{C}\right)\end{array}$ & $\begin{array}{c}\text { Duration } \\
\text { (hr) }\end{array}$ & & \\
\hline \multirow[t]{4}{*}{1} & $8 \pm 1$ & 18 & $8+1$ & 5 & Fert. only & - \\
\hline & & & $13 \pm 2$ & 2 & v & - \\
\hline & & & $18 \pm 1$ & 3 & VIII & - \\
\hline & & & $21 \pm 2$ & 5 & XII & - \\
\hline \multirow[t]{4}{*}{2} & $7 \pm 1$ & 18 & $7 \pm 1$ & 24 & Fert. only & 6 \\
\hline & & & $17 \pm 1$ & $7^{\mathrm{a}}$ & XI & 8 \\
\hline & $17 \pm 1$ & 18 & $7+1$ & 3 & III & 18 \\
\hline & & & $17 \pm 1$ & $7^{\mathrm{a}}$ & XII & 20 \\
\hline \multirow[t]{4}{*}{3} & $10 \pm 0.5$ & 7 & $10 \pm 0.5$ & $18^{b}$ & III & 8 \\
\hline & $12.5 \pm 0.5$ & 7 & $12.5 \pm 0.5$ & 8 & VIII & 7 \\
\hline & $15 \pm 0.5$ & 7 & $15 \pm 0.5$ & 8 & $X I$ & 14 \\
\hline & $21 \pm 1$ & 7 & $21 \pm 1$ & $8^{a}$ & XIII & 12 \\
\hline
\end{tabular}

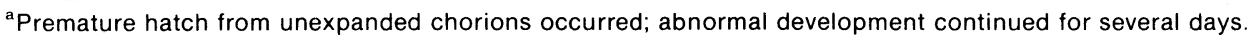

${ }^{\mathrm{b}}$ No development after day 4. 


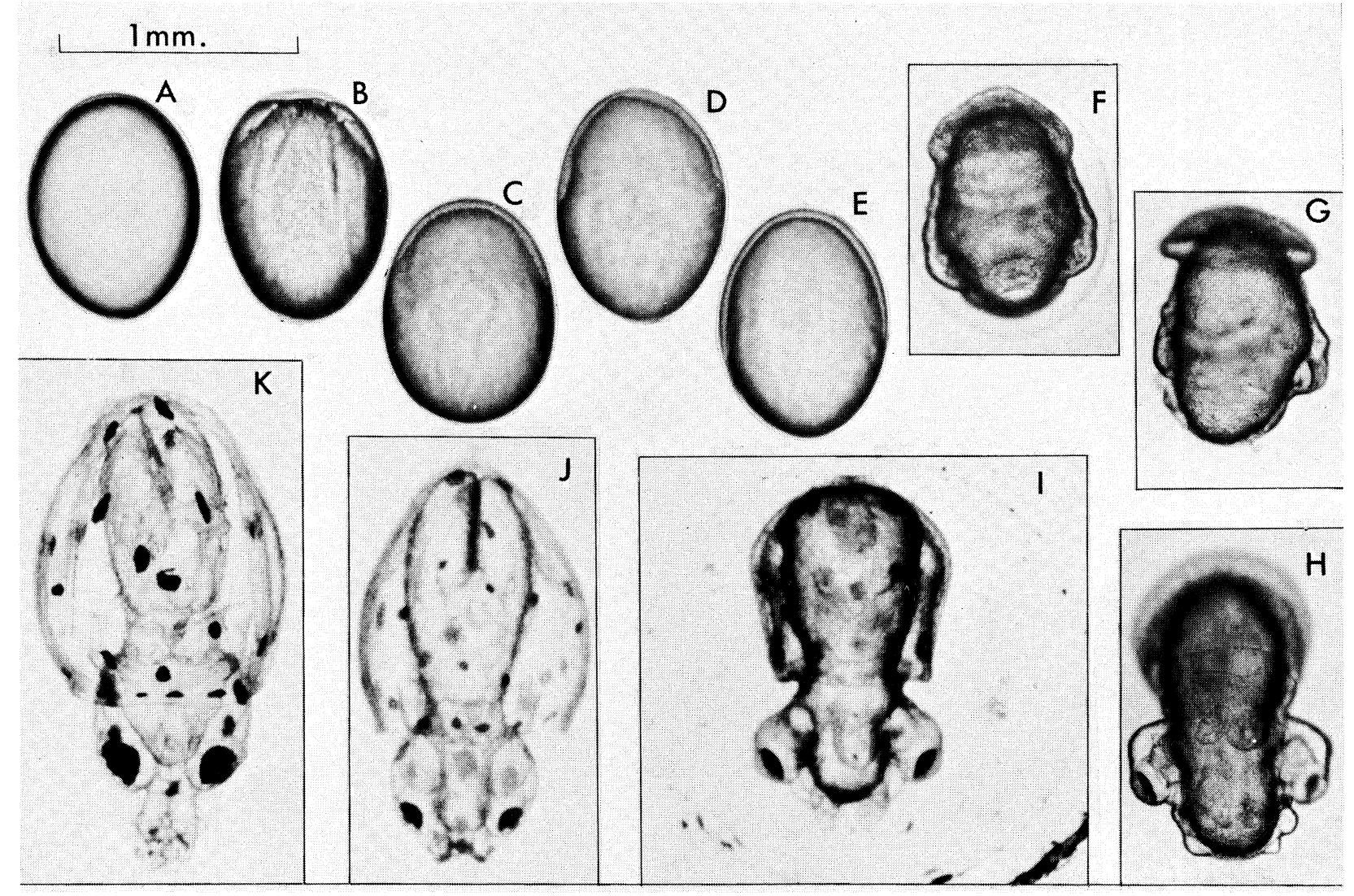

Fig. 1. Egg development in I. illecebrosus based on in vitro (B-E) and in situ observations, with development times relative to $21^{\circ} \mathrm{C}$. A, unfertilized egg. B, fifth cleavage, 5 hours. C, stage III, trilaminar blastoderm forming, one-third of egg celluated, 24 hours. D, stage V, one-half celluate, 2 days. E, stage VII, celluation nearly complete, eye and mouth placodes visibly thickened, 3 days. F, stage IX, mantle development begins, yellow pigmentation of eyes, chorion expanding, 4 days. G, stage XI, arm primordia I, II and IV (tentacles) visible, chromatophores forming on mantle, 5 days. $\mathbf{H}$, stage XIII, mantle reaches mid-line and begins to contract, funnel tube complete, 6 days. I, stage $X V$ in expanded chorion, eye lens and sucker primordia visible, eye stalks and fins prominent, 7 days. J, stage XVII, eyes have moved inward as yolk left cephalopodium, internal yolk sac bifurcates, tentacles fused, mantle covers funnel, 8 days. K, stage XX, yolk nearly consumed, ink sac, fins and buccal mass are functional, extensible proboscis, 9 days. (Staging is based on Naef's (1923) illustrations of 1. coindetii except Stage $\mathrm{XX}$ which is more advanced.)

frequently hatched in situ as early as stage XVII (Fig. $1 \mathrm{~J})$, but in the least disturbed masses they were as advanced as stage $\mathrm{XX}$ (Fig. $1 \mathrm{~K}$ ) when hatching occurred.

\section{Temperature effects}

The in vitro experiments provided information on efficiency of fertilization as well as on development rates at various temperatures (Table 1). For the sperm titers used, maximum fertilization efficiency achieved was only $20 \%$. In preliminary experiments, higher sperm titers resulted in fewer unfertilized eggs, but a higher proportion of eggs expanded, forming a homogeneous layer beneath the chorion. Such eggs did not develop normally, and the proportion of developing eggs never exceeded $30 \%$. In surveys of normally spawned eggs, the proportions of developing eggs were in the range of $6-11 \%$. Fertilization in vitro occurred at temperatures from $7^{\circ}$ to $21^{\circ} \mathrm{C}$ but was more efficient at the higher temperatures.
There are evidently distinct "barriers" to development at low temperatures (Table 1). At $7^{\circ} \mathrm{C}$, the intrachorionic space formed after fertilization but further development did not occur unless temperature was increased. At $10^{\circ} \mathrm{C}$, development proceeded to stage III before stopping. Eggs fertilized at $17^{\circ} \mathrm{C}$ for 18 hours and incubated at $7^{\circ} \mathrm{C}$ developed to stage III and then degenerated in 2-3 days; constrictions formed in the eggs and the cells of the blastoderm became round and dissociated. Abnormal development was also evident at high temperatures. In one instance, eggs from a mass maintained at $17^{\circ} \mathrm{C}$ developed normally when transferred to $22^{\circ} \mathrm{C}$ after 3 days, but eggs from the same mass transferred after 5 days developed with a pocket of yolk embedded in their mantles. In general, the results from in situ observations were similar to those of the in vitro experiments. Eggs that were clearly fertilized failed to develop at temperatures below $12^{\circ} \mathrm{C}$, but eggs in $90 \%$ of the egg masses developed at temperatures between $12^{\circ}$ and $22^{\circ} \mathrm{C}$. 
Complete development occurred at temperatures above $12^{\circ} \mathrm{C}$, but the development rate was highly temperature dependent (Fig. 2). The in vitro observations were made at $12.5^{\circ}, 15^{\circ}$ and $21^{\circ} \mathrm{C}$ and the in situ observations at $13^{\circ}, 17^{\circ}$ and $21^{\circ} \mathrm{C}$. Precise ageing and observation of early development of egg masses is nearly impossible because they are rarely visible until the eggs become more opaque as the embryos develop. Because late stage development was abnor$\mathrm{mal}$ in the in vitro experiments, a complete series of observations can only be obtained by combining both types of data (Fig. 2). The times required for eggs studied in situ to develop from the stage of first observation to later stages at particular temperatures were noted. These records of normal development were aligned with the records of in vitro development by matching the overlapping stages to produce a continuous record. The spawning dates predicted by these lines are 1 or 2 days earlier than those based on the first observation of egg masses.

\section{Discussion}

The problem of distinguishing between the eggs of several species of Ommastrephidae occurring in the range of $I$. illecebrosus in the North Atlantic is similar to the problem of identifying larvae (Roper and Lu, 1979). If photophores develop early in the embryos of genera (Ommastrephes, Ornithoteuthis) other than Illex, they may be a key characteristic in egg identification as they are in larvae (Roper and Lu, 1979). For species of the genus IIlex, there are no known characters that can be distinguished at these early stages, but comparisons of ommastrephid eggs in field collections with the extensive set of reference material available from these experiments may make characterization to species possible in the future.

The pictured embryos (Fig. 1) have been placed within the scheme of development stages given by Naef $(1923,1928)$ for an ommastrephid thought to be $l$. coindetii (Boletzky et al., 1973). Naef's stages have been widely applied in comparative studies of cephalopod embryology (Boletzky, 1974) and their adoption as a standard for ommastrephids seems appropriate. The illustrations in Fig. 1 were chosen to complement Naef's original descriptions by including mainly the odd-numbered stages as well as early stages (III-VII) not illustrated by Naef. It should be noted that the embryo figured by Naef as stage $X X$ should be considered as stage $X I X$, because normal hatching in undisturbed egg masses probably occurs when all of the yolk has been used. Embryos less developed than stage XX (Fig. 1K) may hatch when disturbed, but they are not able to control their swimming and they do not have a functional buccal mass or digestive system. The basic pattern of development observed in I. illecebrosus also appears to apply to $T$. pacificus which has

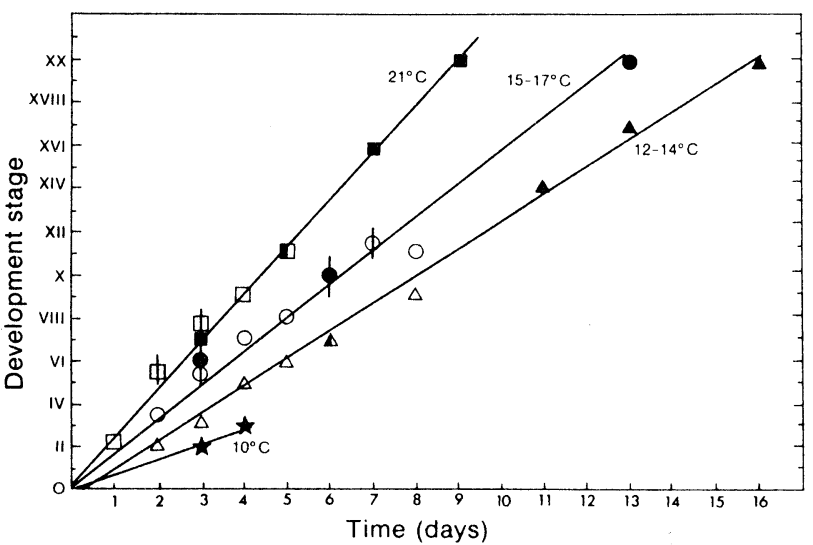

Fig. 2. Relationships between development of I. illecebrosus eggs and time after fertilization for three temperature ranges. (Open and closed symbols are for in vitro and in situ observations respectively; half-filled symbols represent coincident points; bars represent ranges of values when more than one observation was recorded for the same age of egg mass.)

been extensively studied by Japanese workers (Hayashi, 1960; Hamabe, 1962). The eggs of ommastrephid squids are of particular interest because they are among the smallest produced by cephalopods, and a standard for comparison of development stages would be useful.

As an embryologist, Arnold (1965) has criticized Naef's (1923) staging schemes for various cephalopods on the grounds that they describe embryos at equal time intervals over the development period rather than relating them to developmental events of note. There are advantages to having a linear relationship between stage and development time, because, if one wishes to estimate the age of an egg mass, the rate of development $(R)$ can simply be expressed in stages per day. If the times to reach $X X$ are 9,13 and 16 days at mean temperatures $(\mathrm{T})$ of $21^{\circ}, 16^{\circ}$ and $13^{\circ} \mathrm{C}$, as Fig. 2 shows, the respective R's are 2.22, 1.54 and 1.25 stages per day. These values are consistent with a $Q_{10}$ of 1.98 , where $Q_{10}$ is defined by the van't Hoff equation

$$
Q_{10}=\left(R_{2} / R_{1}\right) \exp \left(10 /\left(T_{2}-T_{1}\right)\right)
$$

which predicts the rate of development at any temperature above $13^{\circ} \mathrm{C}$. The approximate age of an egg mass in water of temperature $T$ would equal the average stage number found in the mass divided by the calculated $\mathrm{R}$.

MacMahon and Summers (1971) studied the development rates of the large eggs of the myopsid squid, Loligo pealei, and found a $\mathrm{Q}_{10}$ for "time-tohatch" of above 3.4. This value is outside the normal range of $Q_{10}(2-3)$ for chemically or physically limited processes and may relate to the more complex development pattern in this group which includes formation of an external yolk sac. Various phases of development were differentially affected by temperature. It is not clear whether the lack of such differential effects in the 
present observations reflects the simpler, direct development of ommastrephids or inaccuracies from comparing in vitro and in situ development.

There was some evidence of differential effects of low temperature exposure. The experiments with fertilization at $7^{\circ} \mathrm{C}$ indicate that undeveloped eggs may remain in stasis for a period until the temperature increases. Neither the duration nor the temperature range for such stasis is known. The degeneration of eggs transferred from $17^{\circ}$ to $7^{\circ} \mathrm{C}$ indicates that stasis cannot be entered by advanced stages.

The presence of a temperature minimum above $10^{\circ} \mathrm{C}$ has also been noted for I. coindetii (Boletzky et al., 1973), and there are no records of ommastrephid eggs developing below $13^{\circ} \mathrm{C}$ (Hayashi, 1960; Hamabe, 1962) so that the phenomenon may be general for the group. For successful spawning in I. illecebrosus, which inhabits northern waters and apparently reaches maturity in winter (Amaratunga, MS 1980), the requirement for warm water may be a limiting factor in their range and the underlying cause of their autumn migration. Mid-water spawning in the warm surface waters of the Gulf Stream and North Atlantic Central water mass may be feasible all year, but in winter bottom spawning, as reported for $T$. pacificus (Hamabe, 1962), would only be productive for I. illecebrosus if they migrated over $1,000 \mathrm{~km}$ southward to the continental shelf south of Cape Hatteras.

The low fertilization efficiencies are also of interest. In vitro, sperm move faster but die sooner at higher temperatures, suggesting that there may be an optimum temperature for most efficient fertilization. This matter appears to be significant because most egg masses in situ contained a high proportion of unfertilized eggs. The low fertility may reflect an abnormally low number of spermatophores per female, as the samples of captive animals contained only $5-10 \%$ males each of which probably distributed spermatophores among several females. However, this may not be totally artifactual, as the proportion of males in natural populations also declines as the animals mature (Amaratunga, MS 1980). The in vitro experiments have not adequately explored this problem because the high sperm titers resulted in high proportions of abnormal, non-viable eggs, possibly a result of anoxia under incubation conditions or of polyspermy. A better understanding of the optimum combination of temper- ature, sperm concentration and exposure time should provide more refined insights into the process of mating and spawning in I. illecebrosus. A knowledge of optimum temperature alone would help to delimit the possible spawning sites and times.

\section{Acknowledgements}

We thank the staff of the Aquatron Laboratory, Dalhousie University, Halifax, for their help, cooperation and patience during these prolonged experiments. Support was provided by a collaborative grant from the Canadian Department of Fisheries and Oceans and an operating grant from the National Sciences and Engineering Research Council of Canada.

\section{References}

AMARATUNGA, T. MS 1980. Growth and maturation patterns of the short-finned squid (Illex illecebrosus) on the Scotian Shelf. NAFO SCR Doc., No. 30, Serial No. N062.

ARNOLD, J. M. 1965. Normal embryonic stages of the squid Loligo pealii (LeSueur). Biol. Bull., 128: 24-32.

BOLETZKY, S. V. 1974. Élevage de céphalopodes en aquarium. Vie Milieu, 24A: 309-340.

BOLETZKY, S. V., L. ROWE, and L. AROLES. 1973. Spawning and development of the eggs, in the laboratory, of Illex coindetii (Mollusca: Cephalopoda). Veliger, 15: 257-258.

DURWARD, R. D., E. VESSEY, R. K. O'DOR, and T. AMARATUNGA. 1980. Reproduction in squid, Illex illecebrosus: first observations in captivity and implications for the life cycle. ICNAF Sel. Papers, 6: 7-13.

HAMABE, M. 1962. Embryological studies of the common squid, Ommastrephes sloani pacificus (Steenstrup), in the southwestern waters of the Sea of Japan. Bull. Jap. Reg. Fish. Res. Lab., 10: 1-45.

HAYASHI, S. 1960. Development of the squid, Ommastrephes sloan pacificus (Steenstrup). Nagasaki Daigaku Suisangakubu Kenkyo Hokoku/Bull. Fac. Fish. Nagasaki Univ., 9: 43-48.

MCMAHON, J. J., and W. C. SUMMERS. 1971. Temperature effects on the development rate of squid (Loligo pealei) embryos. Biol. Bull., 141: $561-567$

NAEF, A. 1923. Die cephalopoden. Fauna et Flora di Golfo del Napoli Monographia, 35(2), plates 9-12.

1928. Die cephalopoden. Fauna et Flora di Golfo del Napoli Monographia, 35(2): 186-194.

NAFO. 1980. Report of Standing Committee on Research Coordination. NAFO Sci. Coun. Rep., 1979-80: 91-102.

O'DOR, R. K., R. D. DURWARD, and N. BALCH. 1977. Maintenance and maturation of squid (IIlex illecebrosus) in a 15-m circular pool. Biol. Bull., 153: 322-335.

ROPER, D., and C. C. LU. 1979. Rhynchoteuthion larvae of ommastrephid squids in the western North Atlantic, with the first description of larvae and juveniles of Illex illecebrosus. Proc. Biol. Soc. Wash., 91(4): 1030-1059 
